\title{
MORAL DEVELOPMENT AND MORAL VALUES IN ADOLESCENCE
}

\author{
Ph.D. Elena-Ancuța SANTI, \\ Teacher Training Department, Valahia University Targoviste, Romania. \\ E-mail: santi.anca@yahoo.ro
}

\begin{abstract}
The moral dimension of one's personality is the expression of the existence of man as superior being, actively manifested in knowledge, observance and application of some ethical principles, attitudes, values and norms in our personal life and in relation to the people around and the society. During the years of adolescence, defined by experts as a very important stage in the process of building one's selfidentity, major changes occur at biological, social and cultural level. These changes may be exploited from educational perspective as complex opportunities of the adolescent's formation and development. Knowledge of the needs specific to this age as well as the related individual characteristics, authentic communication and interaction between the adult (parent, teacher) and the teenager, creation of some personal development opportunities and providing moral models and landmarks may be essential in the crystallization process of the moral ego and moral conscience, in this stage of one's life. The expansion of the socialization frontiers, the importance attached to the group of friends, as well as temptations, negative stimuli and nonvalues intensely promoted in the social and the virtual media to which the teenager is exposed, represent direct threats to the moral and ethical integrity of the teenager. In this context, school and family have to be vigilant, discreet and receptive partners who should work together towards a common goal: shaping a nice character, a harmonious, valuable personality, capable of doing what is right in the world. This study aims to explore the teenagers' perceptions of moral values and the manner in which they are set to work in their life; additionally, we seek to identify educational ways and solutions by which the teacher may contribute to the formation and growth of the adolescent as an individual with moral personality and conduct.
\end{abstract}

Keywords: adolescence, character, moral development, moral values

\section{INTRODUCTION}

The experts have asserted that over the past decades the society has gone through a moral crisis as a consequence of the technological and scientific unprecedented progress, loss of moral landmarks and values, decrease in the quality of the education provided by family and school, etc. The most susceptible to these changes are the teenagers. They are receptive to newness and nonconformist and their desire to stand out determine them to take over everything that is out of the ordinary without conducting a thorough analysis; sometimes their choices are good, some other times they are not. Experiencing the age at which the changes at cognitive, emotional and biological level prevail, the teenagers attempt to understand the world in a more profound and abstract way, they analyze, search logical answers and sometimes adopt radical points of view which they strongly support. 
Some researches show that the teenagers' orientations towards morality are contradictory; they consider that moral values are arbitrary and that people should be free to believe and do as they think appropriate (Adams \& Berzonscky, 2009, p. 284); nevertheless, studies state that the pro-social engagements and the care manifested in interpersonal relations emerge during teenage years. In order to understand the morality of the teenagers, the researchers should take into consideration both evolutive changes and situational variations in relation to moral and social judgments (Adams \& Berzonscky, 2009, p. 285).

\section{ADOLESCENCE - PERIOD OF IDENTITY FORMATION}

Adolescence is a special time in the individual's life characterized by multiple and important changes both at physical, mental and social level. As a stage of age ranging from the onset of puberty to acquirement of social independence (Steinberg, 2014), adolescence is a critical period (Curtis, 2015) in the development of the individual, a transition process from childhood to adulthood.

The term "adolescence" originates in the Latin "adolescere"- which means growing up. In most western societies, adolescence was not recognized prior to the $20^{\text {th }}$ century, childhood came to an end and it was the turn of the adulthood when the person reached the age of 18. The contemporary specialists argue that adolescence starts between 10 and 14/15 years (puberty or pre-adolescence), and is followed by the adolescence itself (14/15-18/20 years) and prolonged adolescence (18/20-24/25 years) (Șchiopu, Verza, 1997).

The significant physical, cognitive, emotional and social changes specific to this period make the adolescent feel anxious, insecure, vulnerable, unprepared, both through their rapidity of their manifestation and their intensity.

The adolescent is "invaded" by emotions, under the impact of hormonal changes determining changes of moods, reactions and behaviors unspecific to the previous period. The hormonal changes may influence the teenagers' self-esteem, their happiness, their capacity to focus, aggression, behavioral issues and social relations (Adams \& Berzonsky, 2009, p. 28).

The American psychologist G. Stanley Hall (1904, apud Arnett, 2006, p. 186) states that adolescence would be a stage of "storm and stress", as the adolescent oscillates between the extremes: exuberance and apathy, cruelty and sensitivity, hard-work and inactivity; this is a stage of emotional turmoil and rebellion, in which the teenagers take chances, search extreme sensations and unique experiences, experiment, test their personal limits and seek to continually improve themselves.

E. Verza (2000, p. 185) consider that teenagers do not go through this period at a slow pace; on the contrary, this period involves a lot of turmoil, sometimes some conflicts and dramatic feelings, internal tumult toward finding sources of satisfying one's aspirations, having the tendency to avoid fear of the obstacles which may emerge in connection with their plans and projects for the future. Researchers such as Masterson (1967) or Rutter, Tizard and Whitmore (1970) state that the teenagers are often overwhelmed by anxiety, emotional malaise or even depression in connection with more than half of the cases of normal adolescents under study - samples of ages ranging from 12 to 18 years, most cases being recorded for the age bracket of 14 to 15 years (apud Birch, 2000).

The identity crisis (concept introduced by Erik Erikson, 1963) is specific to this age. Its specific element is the question "Who am I?", question to which the teenager seeks to find an answer. This is a key moment around which the whole life of the individual gravitates 
and which manifests itself through a series of sudden changes, of psychological and social nature, which starts at around 12-14 years for girls and 14-16 years for boys and which consists in a systematic denial of one's previous identity (the child's) and the strong desire to acquire the social status of the adult (Golu, 2015), in the attempt to define their own identity.

Identity includes two concepts (APA, 2002, p. 15): The first is the concept of self, which refers to a set of beliefs of the adolescent in relation to their own person: beliefs on personal (physical or mental) qualities (e.g.: tall, intelligent, funny), roles and goals towards building a career in the future (e.g.: what job he or she will have when they grow up) and interests, values and (religious, political etc) beliefs. The second concept is self-esteem, which involves assessment of what adolescents feel about them, the value (appreciation) assigned by the adolescent to their own self. The global self-esteem refers to the extent to which the adolescent likes or accepts themselves on the whole; the specific self-esteem refers to those parts which the adolescent appreciates about themselves (e.g.: looking good or being a student etc). Self-esteem is a construct formed by social comparison and may undergo, in adolescence in particular, variations depending on some factors: success/failure, expectancies, patterns, models, beliefs, feedback from the others, especially from friends, acceptance/rejection, self-imposed standards etc. According to researches, low self-esteem is associated with a series of manifestations such as (Jaffe, 1998):

- Depression;

- Lack of energy;

- Lack of self-appreciation and rejection of compliments;

- Feelings of insecurity and inadequacy;

- Unrealistic expectations from oneself;

- Feelings of insecurity about the future;

- Excessive shyness and lack of courage when expressing an opinion;

- Conformism in relation to what the others want and acceptance of imposed points of view.

In the context of the formation of one's identity, the experts also mention an originality crisis, which is an active phenomenon of rejection of conventional aspects, characterized by nonconformism, independence and, sometimes, desire for self-improvement (Debesse, 1970 apud Verza, 2000). In their need for independence, the teenager's conduct takes shape and starts to reveal itself through a personal style of participation to social life and the performances obtained. Therefore, the adolescent tries to be original, creative, different, to stand out and to be recognized, to create a style and to find their own place in the world. The need to distinguish from the others, to be unique, comes from the need to discover oneself, to form one's personality and anchor oneself in a stable and profound identity.

All these manifestations contribute to formation of a coherent, secure and sustainable identity, of the self; in case a failure comes to affect acquirement of the identity, the specialists affirm that diffusion (confusion) of the role emerges. This means emergence of a feeling of who and what an individual is (Birch, 2000). An important role in the formation of the identity is played by models for adolescents, parents, teachers, siblings, colleagues, friends or even celebrities, from whom the adolescents borrow attitudes, behaviors, values (or non-values), traits of character, vision of the world and life.

The main construct during the adolescence, the identity also includes the moral self or the moral conscience, which is now modeled and underlies an ethical, moral behavior of the individual in relation to the others around and in society. 


\section{MORAL DEVELOPMENT IN ADOLESCENCE}

Morality was in general defined as the capacity to discern between good and evil (Hart \& Carlo, 2005). Over the past years there has been an increase in the approaches of the morality issues in psychology.

Morality refers to how people relate to principles, norms and values and apply such guidelines in their life, by choosing between good and evil. Each individual makes moral judgments on a daily basis. However, in adolescence, as abstract, logical thinking and emotional and social dimension develop, these judgments are more nuanced, in line with the adolescent's values and beliefs. Moral development refers to changes in moral convictions coming to surface as a person grows and matures. Moral convictions are linked but different from moral behavior: we may know what we should do and yet, in reality, fail adopting a moral behavior.

Moral development is closely connected to cognitive development; the most popular theory on moral development was elaborated by Lawrence Kohlberg (1927 - 1987), an American psychologist who studied the stages undergone by a child while forming moral judgments, starting from moral dilemmas (short fiction stories which describe the situations in which a person is forced to make a moral decision). L. Kohlberg (1984) states that people develop both morally and cognitively in a gradual manner, and moral reasoning becomes increasingly complex as the individual goes from one stage in their life to the next one.

In his theory, Kohlberg (1984) asserts that moral judgment, basis of an ethical behavior, implies six phases of development grouped into three levels: pre-conventional, conventional and post-conventional morality:

- Premoral or pre-conventional level (between 4 and 10 years), in which there is no personal code of morality, and the actions are judged by the consequences arising from complying or breaking the rules. This level has two substages: the stage of morality of listening and the stage of morality of naïve instrumental hedonism.

- Level of conventional morality (between 10 and 13 years), this is the level of conforming to external norms (pleasure in being recognized as having a moral behavior, in being appreciated as a "good" child) and has two substages: the stage of morality of good relations and the stage of law and order morality, in which the feeling of duty and responsibility starts to take shape.

- The level of moral autonomy or interiorization and personal acceptance of moral principles (above 13 years, when young or never), in which acceptance of moral norms emerge as a form of identification with the group of reference, by sharing the same rights or responsibilities. The main characteristic of this level is the maturity of the moral reasoning, materialized in the individual's tendency to detach themselves from the stereotypes existing at a certain time in society and their capacity to define their moral values on their own terms. This is the time when moral judgment becomes rational and interiorized, subordinate to an already assimilated ethical code. The sub-stages are: stage of contractual morality and democratic acceptance of the law and the stage of the morality of individual principles of conduct; this is the time when the person's own system of moral values crystallizes by personal meanings assigned to concepts of justice, reciprocity, equality, dignity. This is the highest stage of moral development - the persons who reach this stage have very strong moral beliefs and convictions. 
Adolescents perceive values, principles, ideas of society in a critical way and try to build their own system of values. They quest their own manner of expression, through behavior and attitudinal constructions and models, through adopting a personal manner of response, through exploration of their own limits. The researches on the formation of a child's character show that the values acquired by such child come, to a large extent, from their personal and social interaction with parents, siblings or other adults within the family (See, 2018; Berkowitz \& Bier, 2005; Lexmond \& Reeves, 2009) or outside it, in particular in the learning environment (See, 2018; APA, 2002; Borba, 2002).

See $(2018$, p. 2) defines the character as a set of behaviors, beliefs and attitudes modeled through the values interiorized by the individual: kindness, justice, respect, honesty, sincerity, loyalty, tolerance, dignity, understanding, altruism etc. The character is not a component of the inborn personality; the character is a component forming as early as childhood and adolescence in particular.

\section{METHODOLOGY}

The objective of this study is to explore the teenagers' perceptions on moral values and how they apply in their life as well as some educational ways and solutions by which the teacher may contribute to the formation and growth of the teenager as a personality possessing moral character and conduct. The research sample was made of 93 high school students. In terms of instruments used to identify teenagers' perceptions on moral values, a questionnaire with various items was specially created and applied.

\section{RESULTS AND DISCUSSIONS}

At item 1 the subjects were requested to choose from a list of terms 5 moral values that are essential to them and to rank them by order of importance assigned, from 1 to 5 , where 1 means a very important value in their life and 5 means the least important of the value chosen. Results are shown in figure 1:

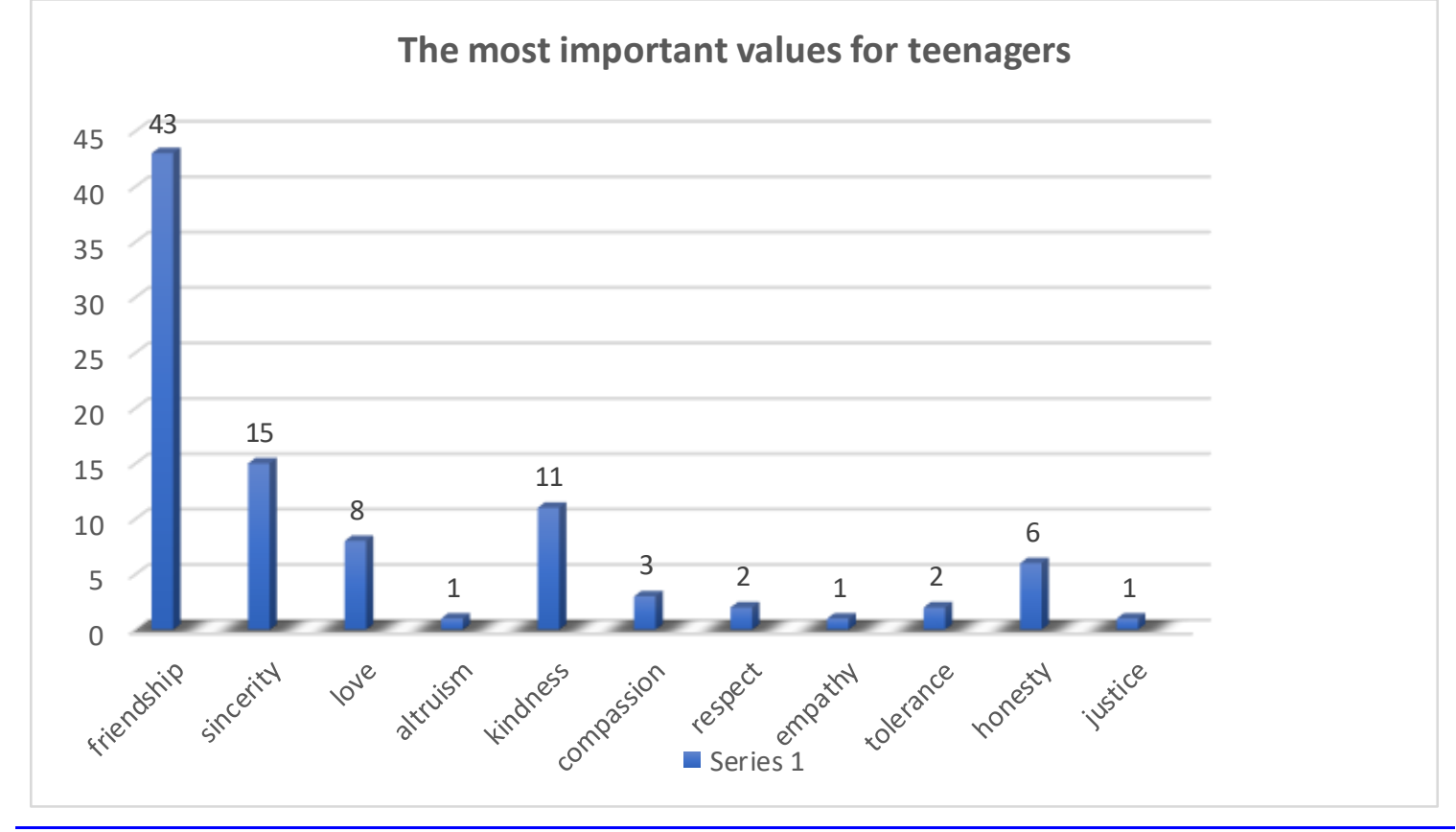

Fig. 1. The values placed in the first place in the students'perception 
Therefore, most teenagers questioned ranked friendship as the most important value in their hierarchy. This fact is also mentioned by the theories in this field, theories which focus on the need to socialization specific to the adolescent and the importance attached at this age to the group of one's friends. Sincerity is another value ranked in first position by 15 teenagers questioned, 11 of the ones questioned consider kindness as the most important value whereas 8 value love. Values which the students failed to mention among the first 5 chosen and prioritized are: commitment, dignity, integrity, patriotism, perseverance.

Item 2 aimed to identify the personal significance assigned by students to the concept of moral character: "What does "having moral character" mean to you"?". Figure 2 summarizes their responses. Therefore, $35 \%$ of the teenagers consider that having moral character means helping others; $27 \%$ consider that the term refers to doing what is good for you, while others, i.e. $22 \%$, judge that having a moral character means doing harm to nobody, $3 \%$ of the students believe that it refers to doing only what you wish to.

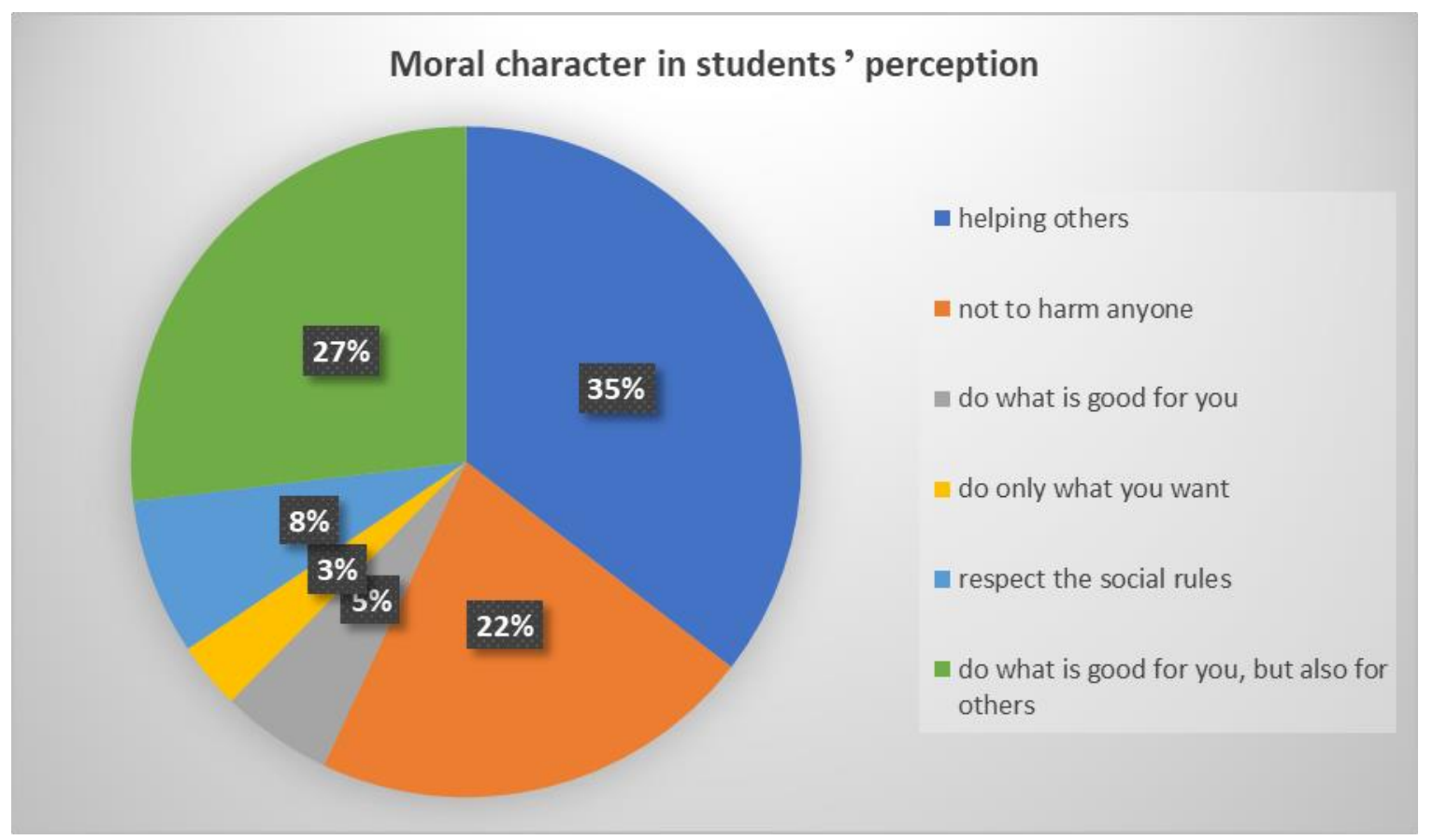

Fig. 2. The personal significance attributed to the concept of moral character

The following item focused on identifying the model considered by teenagers to be a moral landmark in their life. As a consequence, they were requested to fill in the following item with a free answer: "Your model of moral behavior is ...". The results obtained are shown in figure 3 : 


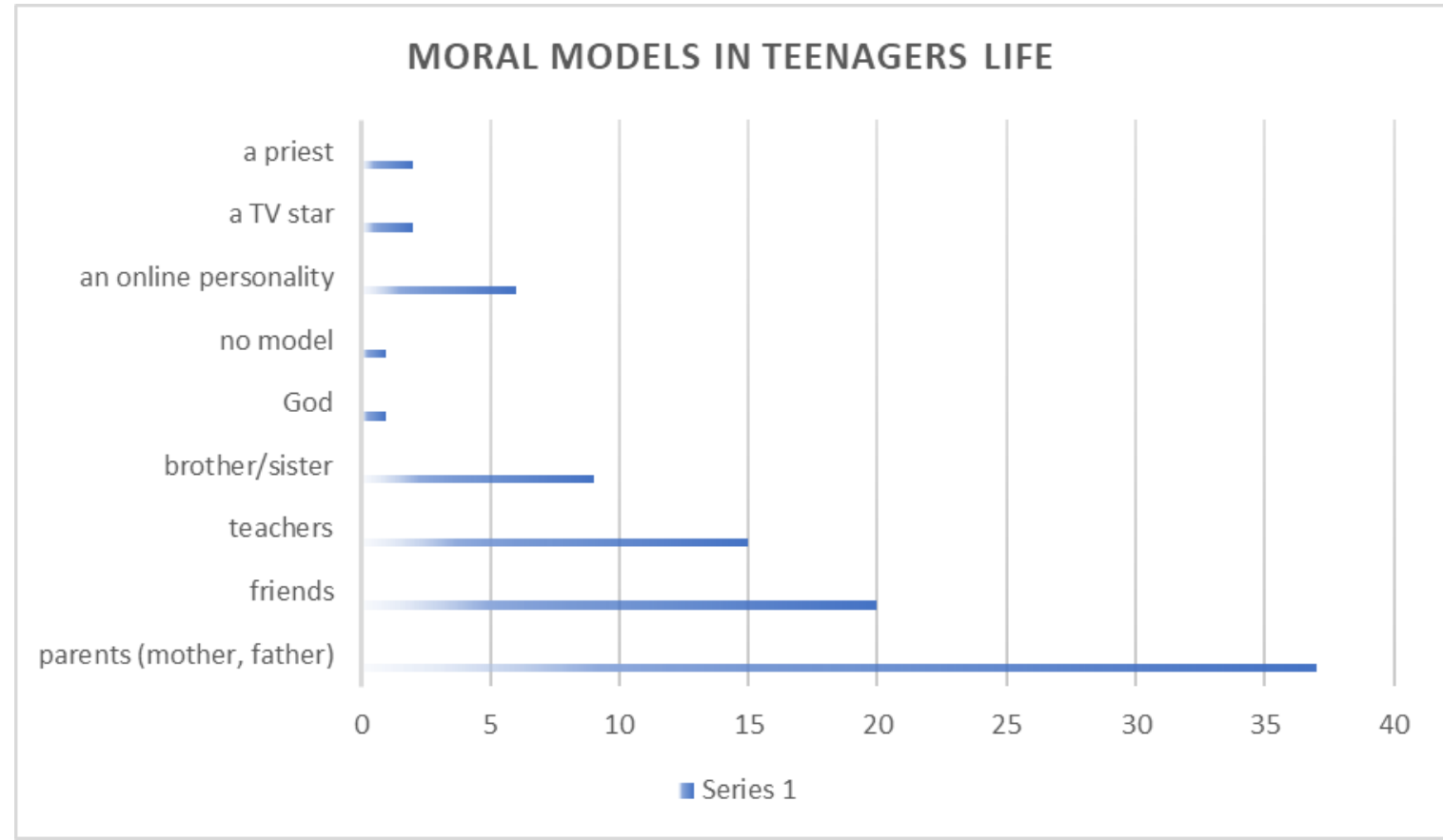

Fig. 3. Adolescents'perception of the moral models in their lives

Most teenagers questioned affirm that their model in life is one of the parents or both; for others, friends are a moral landmark; another category indicates a teacher as their model to follow in life; other responses given: brother/sister, an online celebrity, a TV star, a priest, God or no model at all.

The last item aimed to identify how teenagers perceive themselves as good persons, individuals with moral character: "Do you see yourself as a good, moral person?".

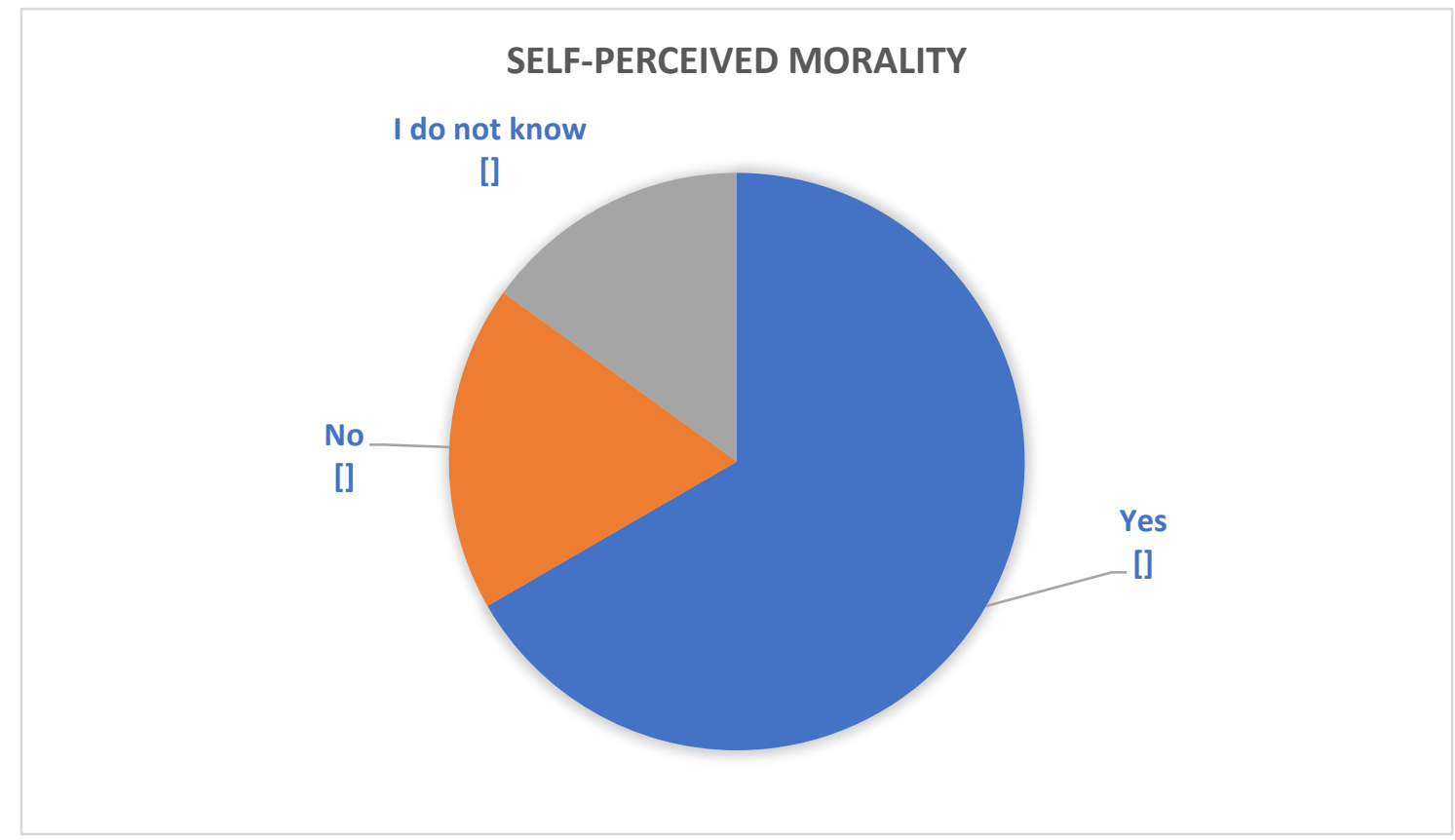

Fig. 4. Adolescents'perception of the moral self 
Figure 4 is a graphic representation of their responses: 67\% of the students questioned have a positive perception of them and consider themselves as good, moral persons. Nevertheless, $18 \%$ of the respondents consider that they are not good persons while $15 \%$ state that they do not know.

\section{CONCLUSIONS}

The researches on moral development in adolescence have significant psychopedagogical implications, as teachers may contribute to the formation of their students' moral character; they may represent models of behavior for the adolescents through principles, values and attitudes which they apply in their life and also through some activities, debates and didactic scenarios of which students are expected to understand and interiorize their own moral schemes.

Additionally, students may be involved in extracurricular and volunteer activities which focus on development of the moral component of their personality. Positive examples from real life may also be provided so as to teach students how to behave in various situations. According to G. Stanley Hall, "adolescence is the time when the best and the worst impulses of the human soul fight for supremacy". Consequently, the adolescent is vulnerable, prone to breaking the rules, eager to stand out, yet anxious, depressive, with oscillating self-esteem, disorientated and insecure. His or her need to be understood, need for affection, respect, freedom, acceptance, confidence and support should be a priority for the adults; although this age is difficult and involves many challenges and changes, the adolescents who communicate and interact with their parents, teachers and other adults in an efficient manner, overcome this age crisis and acquire a self-identity and a strong value sense of one's own person reflected in everything that he or she does.

Being aware of how important the teacher is in forming the students' moral character, it is required of the teacher to have an ethical behavior, based on keeping the promises made, to be objective when assessing, tolerant, respectable, understanding, open to their students, consistent in applying principles and rules; furthermore, the teacher should stimulate the development of altruism, pro-social behavior, care for the others.

Adolescents are receptive to the models that they choose, this is why the family, the school, the friends, the mass-media, the community, the church are all responsible in this respect and may influence the adolescent's value system to a very large extent. 


\section{REFRENCES:}

[1] Adams, G. R., Berzonsky, M. D. (coord.). (2009). Psihologia adolescenței. Manualul Blackwell. Iași: Editura Polirom.

[2] American Psychological Association. (2002). Developing adolescents: A reference for professionals. Washington, DC: American Psychological Society.

[3] Arnett, J. J. (2006). G. Stanley Hall's Adolescence: Brilliance and Nonsense. History of Psychology, 9(3), 186-197. DOI: 10.1037/1093-4510.9.3.186.

[4] Berkowitz, M., Bier, M. (2005). Character education: Parents as partners. Educational Leadership, 63, 64-69.

[5] Birch, A. (2000). Psihologia dezvoltării. București: Editura Tehnică.

[6] Borba, M. (2002). Building moral intelligence: the seven essential virtues that teach kids to do the right thing. San Francisco: Jossey Bass.

[7] Curtis, A. (2015). Defining adolescence. Journal of Adolescent and Family Health, 7(2), Article 2. https://scholar.utc.edu/jafh/vol7/iss2/2.

[8] Erikson, E. H. (1963). Childhood and Society (2nd ed.). New York: W. W. Norton \& Company.

[9] Golu, F. (2015). Manual de psihologia dezvoltării: o abordare psihodinamică. Iași: Editura Polirom.

[10] Hart, D., Carlo, G. (2005). Moral development in adolescents. Journal of Research on Adolescent, 32(3), 223-233.

[11] Jaffe, M. L. (1998). Adolescence. New York: Wiley.

[12] Kohlberg, L. (1984). Essays on Moral Development, Vol. II.: The Psychology of Moral Development: The Nature and Validity of Moral Stages. San Francisco, CA: Harper \& Row.

[13] Lexmond, J., Reeves, R. (2009). Building character. London: DEMOS.

[14] See, B. H. (2018). Understanding the Moral Values of Young People and the Key Influences on their Character Development. Interdisciplinary Education and Psychology, 2(2), 1-32.

[15] Steinberg, L. (2014). Age of opportunity: Lessons from the new science of adolescence. Boston, MA: Houghton Mifflin Harcourt.

[16] Șchiopu, U., Verza, E. (1997). Psihologia vârstelor. Ciclurile vieții. București: Editura Didactică şi Pedagogică.

[17] Verza, E., Verza, F. E. (2000). Psihologia vârstelor. București: Editura Pro Humanitate. 